\title{
Locally induced digital vasospasm detected by delayed rewarming in Raynaud's phenomenon of occupational origin
}

\author{
C JUUL AND S L NIELSEN
}

From the Department of Clinical Physiology, Herlev Hospital, University of Copenhagen, Denmark

ABSTRACT The rewarming time of fingers after hand cooling to $10^{\circ}$ during ischaemia was significantly prolonged in all subjects with Raynaud's phenomenon of occupational origin compared with normal reaction and patients with primary Raynaud's phenomenon. The temperature is faster and easier to record than pressure or pulse volume. Population studies are in progress with the described technique.

An objective test is needed to confirm a patient's history of vibration-induced white finger both in relation to epidemiological studies and in the assessment of disability for industrial injuries benefit. It has, however, proved difficult both to evoke and detect white finger in subjects with Raynaud's phenomenon. ${ }^{12}$

Many different tests have been described (table 1) but their efficiency seems to be unsatisfactory. ${ }^{1}$ The existing cold provocation tests were of minor value in diagnosing Raynaud's phenomenon of occupational origin, and Pyykkö ${ }^{6}$ found a cold test poorly scored in a diagnostic approach. Recently we described a new method for cold provocation using finger cooling to standardised levels during arterial occlusion for five minutes. Attacks are recorded by measuring finger systolic blood pressure. ${ }^{2}$ If the

Requests for reprints to SLN.

Received 7 January 1980

Accepted 12 May 1980 arteries in a cooled segment of a finger are constricted during the cooling a decrease in the finger systolic pressure is recorded. ${ }^{8}$ The method is reasonably accurate in workers having white finger after using vibrating hand tools. ${ }^{7}$ Only one segment of a finger is cooled, however, and it becomes time consuming to map the number of diseased fingers by this method. If stenotic processes are located in the arteries proximal to the cooled segment the test might give falsely normal values. To overcome these problems we have used a standardised cooling procedure of the hand during arterial occlusion at the wrist. ${ }^{910} \mathrm{We}$ have detected induced vasoconstriction by measuring rewarming time from simultaneous recordings of the temperature of the skin on the fingertips.

The sympathetic discharge to the digits was either abolished by body heating or increased by moderate body cooling using a water perfusable blanket. The present study describes the test and compares normal subjects with two groups of patients with Raynaud's phenomenon.

Table 1 Cold provocation tests applied on Raynaud's phenomenon of occupational origin

\begin{tabular}{|c|c|c|c|c|c|c|c|c|}
\hline \multirow[t]{2}{*}{ Author } & \multirow[t]{2}{*}{ Year } & \multicolumn{2}{|c|}{ Local cooling } & \multirow{2}{*}{$\begin{array}{l}\text { Time } \\
(\min )\end{array}$} & \multicolumn{2}{|c|}{ General cooling } & \multirow{2}{*}{$\begin{array}{l}\text { Time } \\
(\min )\end{array}$} & \multirow[t]{2}{*}{ Observation } \\
\hline & & Extent & $\begin{array}{l}\text { Temp } \\
\left({ }^{\circ} \mathrm{C}\right)\end{array}$ & & Extent & $\begin{array}{l}\text { Temp } \\
\left({ }^{\circ} \mathrm{C}\right)\end{array}$ & & \\
\hline Kylin ${ }^{3}$ & 1968 & Hand & 15 & 10 & $\begin{array}{l}\text { Air } \\
\text { Towels }\end{array}$ & $\begin{array}{l}15 \\
15\end{array}$ & 一 & $\begin{array}{l}\text { White finger/delayed } \\
\text { rewarming/pulse } \\
\text { amplitude }\end{array}$ \\
\hline Okada & 1971 & Hand & 4 & 1 & Air & 6 & 一 & White finger \\
\hline Hellstrøm 5 & 1971 & Hand & 15 & 20 & Air & 10 & 40 & White finger \\
\hline Pyykkö ${ }^{6}$ & 1974 & Arm & 15 & 15 & $\begin{array}{l}\text { Air } \\
\text { Towels }\end{array}$ & $\begin{array}{l}20 \\
15\end{array}$ & 15 & White finger \\
\hline Olsen? & 1979 & Finger & 15 & 5 & $\begin{array}{l}\text { Air } \\
\text { Body }\end{array}$ & $\begin{array}{l}22 \\
10-15\end{array}$ & 10 & Finger pressure \\
\hline
\end{tabular}




\section{Material and methods}

Nineteen healthy subjects working indoors and 15 patients with Raynaud's phenomenon volunteered to take part in the study. The normal subjects were either medical students or male hospital employees. The patients were submitted to investigation for Raynaud's phenomenon, and seven were classified by clinical criteria as primary cases (women aged 20-45, attacks from late childhood without rapid deterioration, typical triade of colour shift, no ischaemic signs), and eight as secondary cases (men aged 25-70, attacks after some years of work with vibrating hand tools, typical triade of colour shift released by cold, no ischaemic signs but sometimes lower than normal finger systolic pressure at a finger temperature of $30^{\circ} \mathrm{C}$ ). The age and blood pressure (median and range) measured on the upper arm were for normal subjects 23 years (18-39) and $125 \mathrm{~mm} \mathrm{Hg} \mathrm{(110-160),} \mathrm{for} \mathrm{primary} \mathrm{Raynaud's} 35$ years (22-44) and $133 \mathrm{~mm} \mathrm{Hg}(120-145)$, and for secondary Raynaud's 49 years (26-69) and $135 \mathrm{~mm}$ $\mathrm{Hg}$ (120-170). Patients and normal subjects were investigated supine after 15 minutes' rest at room temperature $\left(22-24^{\circ} \mathrm{C}\right)$. The body was surrounded by a water perfusable blanket perfused either with water at $50-55^{\circ} \mathrm{C}$ or $10-12^{\circ} \mathrm{C}$. The blanket was perfused with hot water for 10 minutes, and during this period thermocouples were applied on the terminal phalanx of the digits for continuous recording of skin temperature using a potentiometer recorder (Ellab Z94 B Copenhagen). A blood pressure cuff at the wrist was inflated to a suprasystolic pressure, and the hand was submerged in water at $10^{\circ} \mathrm{C}$ grasping a precooled metal cylinder. After five minutes the hand was dried by light touch with hand towels. The blood pressure cuff was released without interrupting the recording, which was continued until the skin temperature was above the room temperature. The blanket was thereafter perfused with water at $10-12^{\circ} \mathrm{C}$ for 10 minutes. The finger systolic pressure was recorded with the cuff on the midphalanx of the digit said to have the most pronounced attacks and on the thumb. The finger systolic pressure was measured on the diseased finger (in normal subjects the third finger) after cooling the midphalanx to 30,15 , and $10^{\circ} \mathrm{C} .{ }^{2}$ The thumb was not cooled, and the pressure here was used as reference. Raynaud's phenomenon was observed by a finger pressure of zero indicating complete closure of the digital arteries. ${ }^{8} \mathrm{~A}$ change in arterial constriction was recorded as a pressure drop on the cooled finger. The change was expressed in percentage of the pressure at $30^{\circ} \mathrm{C}$ after correction for changes in the systolic pressure on the reference finger of the same hand. After the pressure recordings the hand cooling to $10^{\circ} \mathrm{C}$ was repeated with continued body cooling.

Statistical evaluation was performed with Wilcoxon's paired sample test in normal subjects and Mann-Whitney's U test or Fisher's exact test for other comparisons, using a level of significance of $5 \%$.

\section{Results}

In normal subjects the rewarming of fingers after hand cooling to $10^{\circ} \mathrm{C}$ was rapid if the body was heated by the water perfusable blanket (table 2). Rewarning time, defined as the time taken for the fingertips to reach room temperature, differed slightly. This difference was significant only when comparing the first and fourth fingers with the fifth finger. Figure 1 shows a temperature curve for a normal subject. After body

Table 2 Rewarming time (min) of fingers to room temperature afier ischaemia and handcooling to $10^{\circ} \mathrm{C}$ in 19 normal subjects after body heating

\begin{tabular}{llllll}
\hline $\begin{array}{l}\text { Finger } \\
\text { No }\end{array}$ & $\begin{array}{l}\text { Mean } \\
(\text { min })\end{array}$ & $S D$ & $f$ & $\begin{array}{l}\text { Mean } \\
95 \%\end{array}$ & $\begin{array}{l}S D \cdot t \\
99 \%\end{array}$ \\
\hline 1 & 1.484 & 0.532 & 18 & 2.41 & 2.84 \\
2 & 1.322 & 0.462 & 17 & 2.13 & 2.51 \\
3 & 1.435 & 0.572 & 16 & 2.43 & 2.91 \\
4 & 1.411 & 0.488 & 18 & 2.26 & 2.66 \\
5 & 1.263 & 0.465 & 18 & 2.07 & 2.45 \\
\hline
\end{tabular}

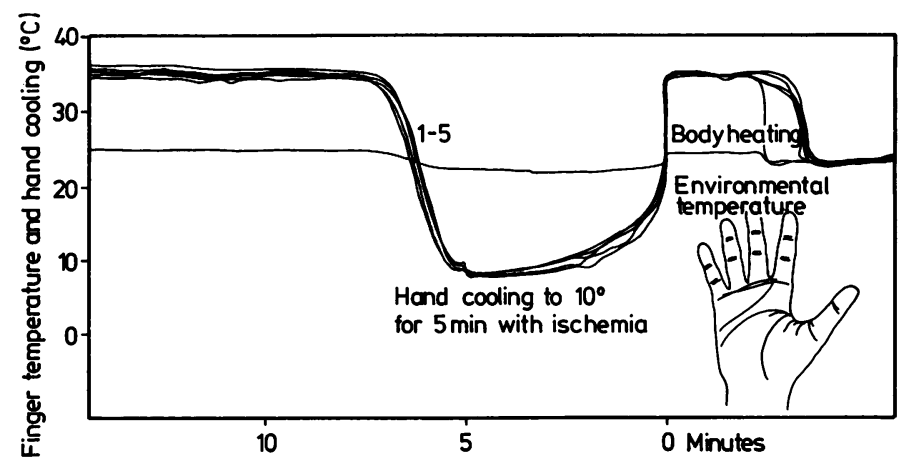

Fig 1 Temperature recordings on fingertips before, during, and after cooling of hand with water at $10^{\circ} \mathrm{C}$. Ischaemia was obtained by an occluding cuff at wrist during five minutes' cooling. Note that in normal subject all finger temperatures crossed room temperature within 2.5 minutes. 
Table 3 Rewarming time (min) of fingers to room temperature after handcooling at $10^{\circ} \mathrm{C}$ for 5 minutes during ischaemia. Nineteen normal subjects and 15 patients with Raynaud's phenomenon compared with Mann-Whitney's rank test

\begin{tabular}{|c|c|c|c|c|c|c|c|c|}
\hline \multirow[t]{2}{*}{ Finger } & \multicolumn{2}{|c|}{ Normal subjects $(n=19)$} & \multicolumn{2}{|c|}{ Primary Raynaud's $(n=7)$} & \multicolumn{2}{|c|}{ Secondary Raynaud's $(n=8)$} & \multicolumn{2}{|l|}{$p$-value } \\
\hline & Median & Range & Median & Range & Median & Range & $N v S$ & $P v S$ \\
\hline $\begin{array}{l}1 \\
2 \\
3 \\
4 \\
5\end{array}$ & $\begin{array}{l}1 \cdot 4 \\
1 \cdot 3 \\
1 \cdot 3 \\
1 \cdot 3 \\
1 \cdot 4\end{array}$ & $\begin{array}{l}0 \cdot 7-2 \cdot 5 \\
0 \cdot 6-2 \cdot 9 \\
0 \cdot 6-2 \cdot 9 \\
0 \cdot 5-2 \cdot 3 \\
0 \cdot 4-2 \cdot 1\end{array}$ & $\begin{array}{l}1 \cdot 2 \\
1 \cdot 3 \\
1 \cdot 3 \\
1 \cdot 2 \\
1 \cdot 7\end{array}$ & $\begin{array}{l}1 \cdot 0-1 \cdot 8 \\
0 \cdot 9-10 \cdot 0 \\
0 \cdot 8-9 \cdot 5 \\
0 \cdot 7-8 \cdot 6 \\
0 \cdot 8-7 \cdot 0\end{array}$ & $\begin{array}{l}2 \cdot 3 \\
3 \cdot 0 \\
6 \cdot 2 \\
6 \cdot 5 \\
4 \cdot 4\end{array}$ & $\begin{array}{l}0 \cdot 9-3 \cdot 8 \\
1 \cdot 1-12 \cdot 6 \\
0 \cdot 9-13 \cdot 0 \\
2 \cdot 8-10 \cdot 5 \\
2 \cdot 1-10 \cdot 2\end{array}$ & $\begin{array}{l}<0.05 \\
<0.01 \\
<0.01 \\
<0.01\end{array}$ & $\begin{array}{l}>0.05 \\
>0.05 \\
<0.05\end{array}$ \\
\hline
\end{tabular}

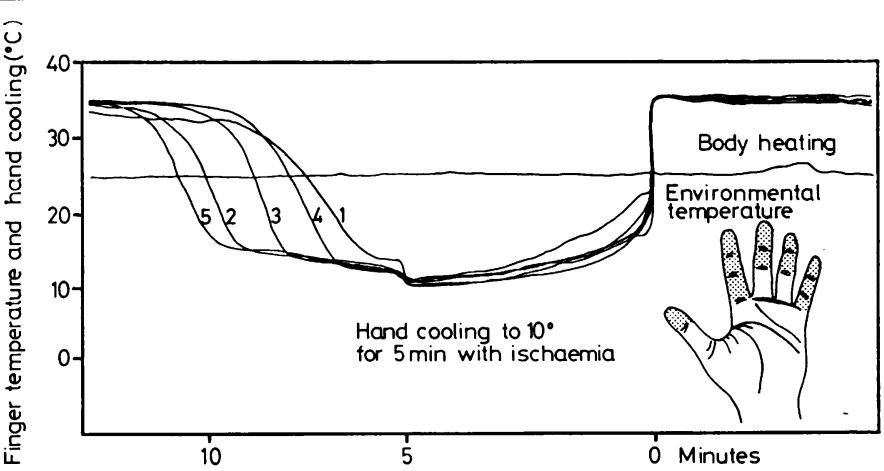

Fig 2 Temperature recordings in a patient complaining of Raynaud's phenomenon of occupational origin in all fingers. Note a prolonged rewarming time compared to normal reaction (table 2).

Table 4 Comparison of rewarming time with secondary Raynaud's record of white, dead fingers at cold exposure. $p<0.01$ with Fisher's exact test

\begin{tabular}{lll}
\hline Rewarming & Finger white & Normal \\
\hline Prolonged & 22 & 1 \\
Normal & 1 & 5 \\
\hline
\end{tabular}

Table 5 Comparison of rewarming time on diseased fingers from patients record in primary and secondary forms of Raynaud's phenomenon. $p<0.01$ with Fisher's exact test

\begin{tabular}{lll}
\hline Rewarming & Primary Raynaud's & Secondary Raynaud's \\
\hline Prolonged & 11 & 22 \\
Normal & 19 & 1 \\
\hline
\end{tabular}

cooling, the rewarming time was much more variable in normal subjects, and some did even not reach room temperature on the digits within half an hour. Therefore the standard test to be used in patients with Raynaud's phenomenon was chosen to be hand cooling during body heating to abolish the sympathetic discharge to the digits. Table 2 gives the normal range and confidence limits for the rewarming time.

For two groups of patients with Raynaud's phenomenon, the reaction of the digits to hand cooling during body heating is shown in table 3 . Patients with Raynaud's phenomenon of occupational origin all showed an abnormal, prolonged rewarming time that seemed related to the patient's record of severity in each finger. A prolonged rewarming time

Table 6 Arm and finger systolic blood pressure in 19 normal indoor workers and 15 patients with Raynaud's phenomenon (median and range)

\begin{tabular}{|c|c|c|c|c|c|c|}
\hline \multirow[t]{2}{*}{ Group } & \multirow[t]{2}{*}{$N o$} & \multirow[t]{2}{*}{$\begin{array}{l}\text { Arm systolic blood } \\
\text { pressure }\end{array}$} & \multirow[t]{2}{*}{$\begin{array}{l}\text { Finger systolic } \\
\text { pressure }\end{array}$} & & \multicolumn{2}{|c|}{$\begin{array}{l}\text { Finger systolic pressure in percentage of } \\
\text { pressure at } 30^{\circ} \mathrm{C}\end{array}$} \\
\hline & & & & & $15^{\circ}$ & $10^{\circ}$ \\
\hline $\begin{array}{l}\text { Normal } \\
\text { subjects }\end{array}$ & 19 & $\begin{array}{l}125 \\
110-160\end{array}$ & $\begin{array}{l}125 \\
95-168\end{array}$ & $*$ & $\begin{array}{l}90 \\
68-117\end{array}$ & $\begin{array}{l}83 \\
62-98 \\
*\end{array}$ \\
\hline $\begin{array}{l}\text { Primary } \\
\text { Raynaud's }\end{array}$ & & $\begin{array}{l}132 \\
120-145\end{array}$ & $\begin{array}{l}127 \\
108-146\end{array}$ & $*$ & $\begin{array}{l}66 \\
*\end{array}$ & ${ }_{*}^{63} 0-88$ \\
\hline $\begin{array}{l}\text { Secondary } \\
\text { Raynaud's }\end{array}$ & 8 & $\begin{array}{l}135 \\
120-170\end{array}$ & $\begin{array}{l}119 \\
106-135\end{array}$ & $*$ & $\stackrel{49}{0-66}$ & $\begin{array}{l}0 \\
0-59\end{array}$ \\
\hline
\end{tabular}

* Denote significant difference ( $p<0.05$ with Wilcoxon test for paired differences and Mann-Whitney's test for grouped samples). 
was observed only in the women having pronounced primary Raynaud's phenomenon. An example of the temperature curves is given in fig 2 where all diseased fingers showed a prolonged rewarming time compared with the normal values (table 2). If the number of digits with clinical disease is compared with the number of abnormal test results in secondary and primary Raynaud's phenomenon only secondary cases have a significant relation $(p<0.01$, table 4$)$. Comparing the test results on diseased fingers in primary and secondary Raynaud's phenomena gave a significant difference $(\mathrm{p}<0.01$, table 5). Table 6 gives the results of the finger systolic pressure measurements on the three groups. It is evident that the finger systolic pressure in secondary cases is lower and the reaction to finger cooling is more pronounced than in the other groups.

\section{Discussion}

Raynaud's phenomenon is provoked by combined local and general cooling (table 1), and the phenomenon may either be observed directly or be recorded by a prolonged rewarming time or the absence of the pulse, zero pressure, or absent blood flow in the finger. Tests previously described have not standardised the cold provocation in ways other than by the temperature of the water (or air) and the exposure time. ${ }^{11}$ In the technique presented here, the temperature of the finger arteries was made to come down to skin temperature by cooling for five minutes during hand ischaemia. This principle was proposed by Krähenbühl ${ }^{10}$ and validated by Nielsen. ${ }^{2}$

Sympathetic discharge is, however, important for the release of Raynaud's phenomenon, and unknown sympathetic activation is hidden in the tests described earlier (table 1). Our novel approach is to avoid influencing the sympathetic nervous system by heating the body before cooling the hand. Theoretically, this should exclude cases of Raynaud's phenomenon in which the sympathetic nervous system alone is responsible for the attacks. Two-thirds of the patients classified as having primary Raynaud's phenomenon showed a completely normal rewarming time (table 5).

In all cases of Raynaud's phenomenon of occupational origin the rewarming time was prolonged (table 4) and the more prolonged, the more affected were the fingers. The new technique was more sensitive than the test using finger systolic pressure after local cooling. This is probably due to more extensive hand cooling.
The present test is unable to give information about the existence of stenotic processes in the finger or hand arteries. A study on patients undergoing hand arteriography is therefore in progress. Another problem is to decide the predictive value of the described test.This can be done only with a population study, which will be started when a simplified temperature recorder has been developed giving information only about the rewarming time for each finger. In describing the severity of Raynaud's phenomenon both the number of digits affected and the critical temperature for release of the attacks are important. The technique described here gives information about the number of digits affected in secondary cases, and the critical temperature might be determined by cooling to different temperature levels-for example, 20,15 , and $10^{\circ} \mathrm{C}$. Each level takes, however, about 10-15 minutes to record and the test thereby becomes rather time consuming. It is advisable to estimate the critical temperature by a detailed medical interview.

\section{References}

${ }^{1}$ Taylor W, Pelmear PL. Vibration white finger in industry. London: Academic Press, 1975.

${ }^{2}$ Nielsen SL. Raynaud phenomena and finger systolic pressure during cooling. Scand J Clin Lab Invest 1978;38: 765-70.

${ }^{3}$ Kylin B, Gerhardsson G, Hansson J-E, et al. Hälso-och miljö undersökning bland skogsarbetate. Stockholm: Arbejdsmedicinska Institutet, 1968. (A I rapport 5.)

4 Okada A, Yamashita T, Nagano C, Ikeda I, Yachi A, Shibata $\mathbf{S}$. Studies on the diagnosis and pathogenesis of Raynaud's phenomenon of occupational origin. $\mathrm{Br} J$ Ind Med 1971;28:353-7.

${ }^{5}$ Hellstrøm B, Myhre K. A comparison of some methods of diagnosing Raynaud phenomena of occupational origin. Br J Ind Med 1971;28:272-9.

6 Pyykkö I. The prevalence and symptoms of traumatic vasospastic disease among lumberjacks in Finland. A field study. Work-environm.-hlth 1974;11:118-31.

${ }^{7}$ Olsen N, Nielsen SL. Diagnosis of Raynaud's phenomenon in quarry men's traumatic vasospastic disease. Scand $J$ Work Env Health 1979;5:249-56.

${ }^{8}$ Krähenbühl B, Nielsen SL, Lassen NA. Closure of digital arteries in high vascular tone states as demonstrated by measurement of systolic blood pressure in the fingers. Scand J Clin Lab Invest 1977;37:71-6.

9 Jepson RP. The effects of vascular occlusion and local cooling on finger skin blood flow. Clin Sci 1954;13:25965.

${ }^{10}$ Krähenbühl B. Une Méthode utilé pour le diagnostic du phénoméne de Raynaud: la suppression par le froid de l'hyperémie réactionelle post-ischémique digitale. Schweiz Med Wochenschr 1977;107:1831-3.

11 Chang C-P. Cold water immersion test in patients with vibration disease. Jap J Ind Health 1976;18:453-63. 